\title{
The effectiveness and safety of pulmonary autograft as living tissue in Ross procedure: a systematic review
}

\author{
Francesco Nappi ${ }^{1}$, Adelaide Iervolino ${ }^{2} \wedge$, Sanjeet Singh Avtaar $\operatorname{Singh}^{3} \wedge$ \\ ${ }^{1}$ Department of Cardiac Surgery, Centre Cardiologique du Nord, 93200 Saint-Denis, France; ${ }^{2}$ Department of Internal Medicine, Federico II \\ University, Naples, Italy; ${ }^{3}$ Department of Cardiothoracic Surgery, Golden Jubilee National Hospital, Glasgow, UK \\ Contributions: (I) Conception and design: F Nappi; (II) Administrative support: F Nappi, SS Avtaar Singh; (III) Provision of study materials or \\ patients: F Nappi; (IV) Collection and assembly of data: All authors; (V) Data analysis and interpretation: F Nappi, A Iervolino; (VI) Manuscript \\ writing: All authors; (VII) Final approval of manuscript: All authors. \\ Correspondence to: Francesco Nappi, MD. Cardiac Surgery, Centre Cardiologique du Nord de Saint-Denis, 36 Rue des Moulins Gémeaux,93200 \\ Saint-Denis, France. Email: francesconappi2@gmail.com.
}

Background: Reports on effectiveness and safety after the implant of pulmonary autograft (PA) living tissue in Ross procedure, to treat both congenital and acquired disease of the aortic valve and left ventricular outflow tract (LVOT), show variable durability results. We undertake a quantitative systematic review of evidence on outcome after the Ross procedure with the aim to improve insight into outcome and potential determinants.

Methods: A systematic search of reports published from October 1979 to January 2021 was conducted (PubMed, Ovid Medline, Ovid Embase and Cochrane library) reporting outcomes after the Ross procedure in patients with diseased aortic valve with or without LVOT. Inclusion criteria were observational studies reporting on mortality and/or morbidity after autograft aortic valve or root replacement, completeness of follow-up $>90 \%$, and study size $\mathrm{n} \geq 30$. Forty articles meeting the inclusion criteria were allocated to two categories: pediatric patient series and young adult patient series. Results were tabulated for a clearer presentation.

Results: A total of 342 studies were evaluated of which forty studies were included in the final analysis as per the eligibility criteria. A total of 8,468 patients were included (7,796 in pediatric cohort and young adult series and 672 in pediatric series). Late mortality rates were remarkably low alongside similar age-matched mortality with the general population in young adults. There were differences in implantation techniques as regard the variability in stress and the somatic growth that recorded conflicting outcomes regarding the miniroot vs the subcoronary approach.

Discussion: The adaptability of lung autograft to allow for both stress variability and somatic growth make it an ideal conduit for Ross's operation. The use of the miniroot technique over subcoronary implantation for better adaptability to withstand varying degrees of stress is perhaps more applicable to different patient subgroups.

Keywords: Pulmonary autograft; root remplacement; subcoronary implantation; Ross operation

Submitted Jul 29, 2021. Accepted for publication Jan 14, 2022.

doi: $10.21037 / \mathrm{tp}-21-351$

View this article at: https://dx.doi.org/10.21037/tp-21-351

^ ORCID: Adelaide Iervolino, 0000-0002-3208-4689; Sanjeet Singh Avtaar Singh, 0000-0003-4320-0734. 


\section{Introduction}

In patients with somatic growth potential, the benefits of using a pulmonary autograft $(\mathrm{PA})$ in the Ross procedure are related to the use of living tissue (pulmonary valve and conduit) which has demonstrated favourable hemodynamic characteristics, low risk of endocarditis, low thrombogenicity, avoidance of lifelong anticoagulation, and natural growth of autograft to match somatic growth (1-5). However, the primary concern related to the use of the technically challenging Ross procedure that is burdened by the possibility of developing structural valve deterioration (SVD) over time, leading to failure of PA implanted in the aortic position as well as of the valve substitute inserted for the reconstruction of the right ventricular outflow tract (RVOT) (5-10).

Despite the safety and effectiveness profile alongside results comparable to the general population effectiveness in recipients of the Ross procedure in the paediatric cohort and young adult patients, the use of the PA has improved durability in some centers. In fact, in these institutions, patients who were managed for aortic valve disease and/or left ventricular outflow tract (LVOT) with the use of Ross procedure revealed significantly higher efficacy of PA over time compared to other biological valve substitutes, with converse results in patients receiving a Ross procedure in other centres where the reintervention rate of the implanted $\mathrm{PA}$ is higher (4,11-15).

The reasons for this clear divergence in the results are not well established and necessitate further review. We, therefore, performed a systematic review of the literature for an objective evaluation of the evidence provided by the literature. The results reported in our study could therefore help clarify uncertainty by synthesizing results from original research, reviews and editorials. We believe that a careful analysis of the available evidence relating to the differences in mortality and morbidity presented after the Ross procedure will provide greater clarity on outcomes.

The objective of this systematic review is to examine observational and prospective reports on mortality and morbidity, and to evaluate patient-related factors. We examined the surgical techniques used in the Ross procedure performed during the somatic growth phase and analyzed the histological and mechanical aspects of living PA tissue in order to improve the understanding of the potential determinants of success after using the PA.

We present the following article in accordance with the PRISMA reporting checklist (available at https:// tp.amegroups.com/article/view/10.21037/tp-21-351/rc).

\section{Methods}

\section{Search strategy}

We designed this systematic review drawing information from the report of Stroup et al. (16). The coordinating center was set in France; 1 reviewer were based in France and 1 reviewer in Italy to collect data $(16,17)$.

We conducted an electronic search of PubMed (1988 to present), Ovid Medline (1946 to present) and Ovid Embase (1974 to present) that run on January 1st 2021 with the following targeted words: aortic valve replacement and pulmonary autograph, aortic valve replacement and Ross procedure, aortic valve replacement and Ross operation. We assessed a large number of publications from 1979 and 2021 in patients who received the Ross Operation for aortic valve replacement in the age of somatic growth with or without reconstruction of LVOT. To ensure completion, we conducted a search of the Cochrane library (1993 to present) using the key words, autograft aortic valve replacement or Ross procedure or Ross operation to access title and abstracts for detailed analysis of manuscript. This review followed the Preferred Reporting Items for Systematic Reviews and Meta-analyses (PRISMA) reporting guideline (16-19).

\section{Data extraction}

Searches retrieved 2,181 results. Three reviewers (FN, SSAS, AI) were commissioned to screen the literature and analyzed the titles and abstracts, against predefined inclusion and exclusion criteria, of all selected studies judged relevant to the systematic review. Animal studies, case reports, conference presentations, editorials, expert opinions, and observational studies were excluded. A statistical reviewer assessed whether inclusion and exclusion were performed correctly. All disagreements were solved by discussion within the research team with the help of FN if needed to reach a consensus.

We have given particular attention to the studies they had a follow-up $>90 \%$ and studies with $\geq 30$ patients, reflecting the high level of center experience. In cases where multiple publications have emerged from the same patient population (see Deutsch registry for Ross Operation), we have selected the most recent report and meticulously analysed the statistical methodology used. Above all, 

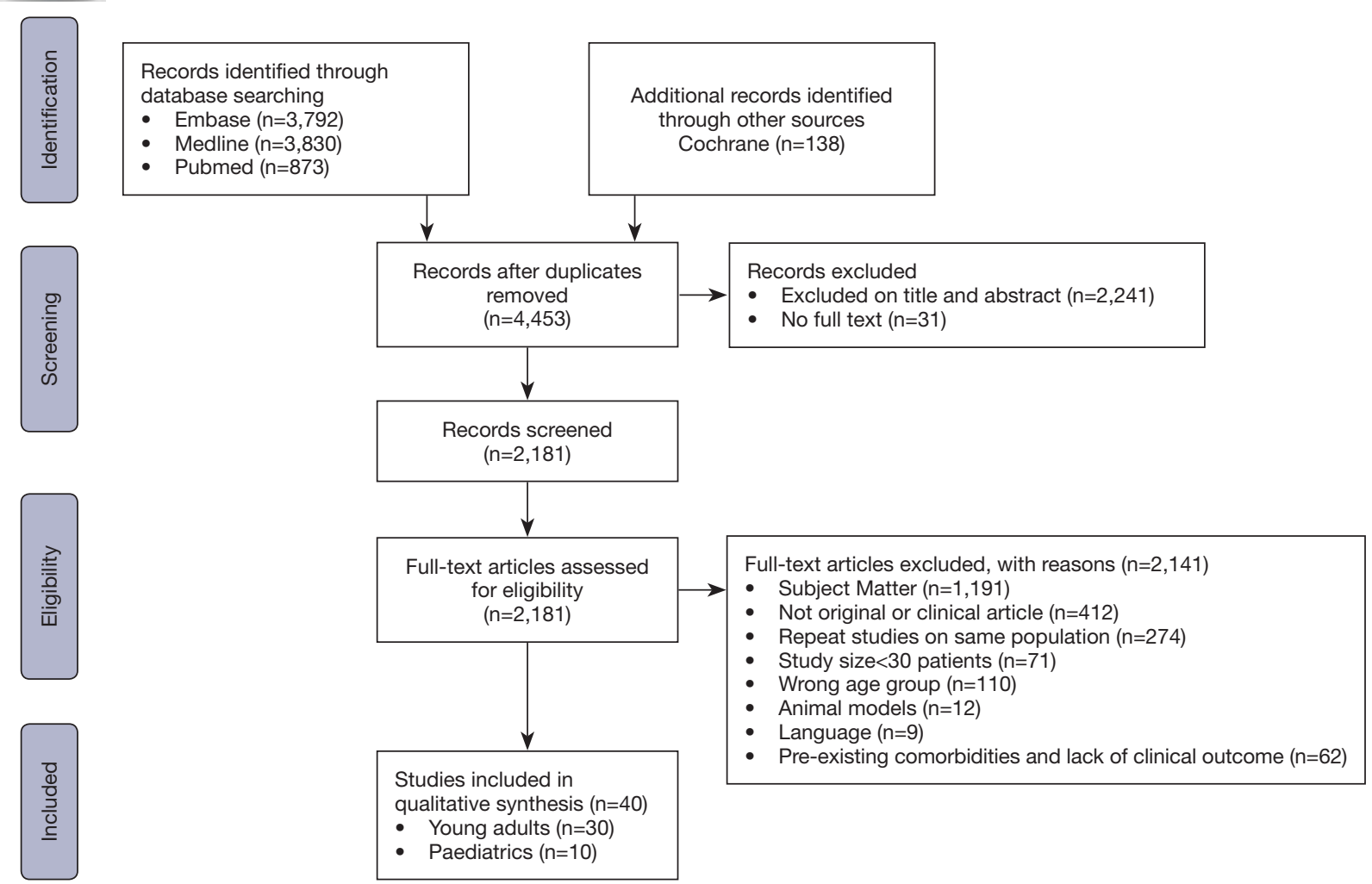

Figure 1 Prisma flow diagram.

randomized controlled trials were chosen (16-19).

Microsoft Excel was used to include data extraction. The following variables were extracted: study data and location, study type, study period, number of patients enrolled, mean age and mean length of follow-up. The potential age heterogeneity of the patients included in the publications was overcome by considering 3 categories of recipients of the Ross procedure. (I) Consecutive series of Ross procedures performed in children were included; (II) consecutive series of Ross procedures performed on young adult and child populations were included; (III) consecutive series of Ross procedures performed on the adult population were excluded.

The target outcomes incorporated indication for surgery and procedure used. Mortality and/or morbidity, after aortic valve replacement were evaluated in patients who received autograft aortic valve or root replacement. Outcome events were recorded according to the 2020 ACC/AHA, 2020, 2017 American Thoracic Surgery/Society of Thoracic Surgeons/European Association for Cardiothoracic Surgery guidelines $(19,20)$.

The primary outcomes were early and late mortality, as absolute values or rates. Secondary endpoints were structural/non-structural valve deterioration, defined both for reoperation required and or autopsy, bleeding, thromboembolism, and valve thrombosis $(16,17)$.

\section{Results}

A total of 342 studies were evaluated of which forty studies included and 302 excluded in the final analysis as not meeting eligibility criteria. The full PRISMA flow diagram outlining the study screening process is reported in Figure 1. PRISMA 2020 Checklist Item are enclosed in Reporting Checklist. The details of the eligibility criteria of manuscripts are reported in Tables 1,2.

A total of 8,468 patients were included (7,796 in pediatric cohort and young adult series and 672 in paediatric series).

The major finding of this study revealed considerable experience with the use of Ross procedure accumulated by 
Table 1 Overview of studies obtained by systematic review reporting young adult and pediatric series of ross operation

First author/year of publication (Ref) Study type Period of Number of Mean age, y

Aboud 2021 (21), JACC, Germany

Nappi 2018 (22), ICVTS, France

Sievers 2016 (15), EJCTS, Germany

Andreas 2014 (23), Annals, Germany

da Costa 2014 (24), Eur J Cardiothorac Surg, Brasil

Ruzmetov 2012 (25), Ann Thorac Surg, USA

Luciani 2012 (26), EJCTS, Italy

Böhm 2009 (27), Ann Thorac Surg, Germany

Elkins 2008 (11), JTCVS, USA

Klieverik 2008 (28), EHJ, Holland

Klieverik* 2007 (29), EHJ, Holland

Chiappini 2007 (30), Ann Thorac Surg

Pasquali 2007 (31), JTCVS

Brown 2007 (32), Ann Thorac Surg, USA

Kumar 2005 (33), Ann Thorac Surg

Sampath Kumar 2006 (34), Eur J Cardiothorac Surg

Kouchoukos 2004 (35), Ann Thorac Surg, USA

Raja 2004 (36), BMC Cardiovasc Disord, UK

Alphonso 2004 (37), Eur J Cardiothorac Surg

Sakaguchi 2003 (38), J Heart Valve Dis

\begin{tabular}{cccc} 
Study type & $\begin{array}{c}\text { Period of } \\
\text { surgery }\end{array}$ & $\begin{array}{c}\text { Number of } \\
\text { patients (N) }\end{array}$ & $\begin{array}{c}\text { Mean age, } \\
\text { [range] }\end{array}$ \\
\hline Retrospective & $1988-2001$ & 2,244 & 33 [16-61]
\end{tabular}

Surgical technique

Mean follow-up Early mortality, Late mortality, \% Autograft $\quad$ RVOT SVD/NSVD, TE/BLNT, \%

Autograft
endocardits,

$\begin{array}{lc}\text { RVOT } \\ \text { Alaft } & \text { RV } \\ & \end{array}$

Retrospective $\quad 1988-2001 \quad 2,244 \quad 33[16-61] \quad$ Root/reinforced root/non reinforced subcoronary

Retrospective $1998-2002 \quad 66 \quad 29$ [16mth-62] Root/reinforced root/non reinforced subcoronary

(years)

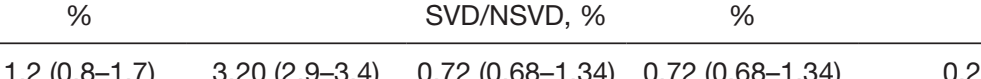

0.38

$0.09(0.04-0.52)$

Retrospective/ $1990-2013 \quad 1,779 \quad 31[16-40] \quad$ Root/reinforced root/non reinforced subcoronary

$1.3(0.7-1.6) \quad 3.25(2.9-3.5) \quad 0.68(0.63-1.32) \quad 0.64(0.60-1.28) \quad 0.28$

$0.40 \quad 0.10(0.05-0.60)$

prospective

Retrospective $1991-2011 \quad 246 \quad 25[5-46]$

Retrospective $1995-2013 \quad 441 \quad 31[5-56]$

Retrospective $1990-2011 \quad 106 \quad 18[1 \mathrm{mth}-40]$

Retrospective $\quad 1994-2004 \quad 112 \quad 29[6-49]$

Retrospective $\quad 1995-2006 \quad 467 \quad 41[26-56]$

Retrospective $\quad 1986-2002 \quad 487 \quad 24[2-62]$

Prospective $\quad 1987-2007 \quad 63 \quad 29[16-52]$

Prospective $\quad 1988-2005 \quad 146 \quad 22[0.3-52]$

Retrospective $\quad 1991-2005 \quad 219 \quad 36[0.5-64]$

Retrospective $1995-2004 \quad 121 \quad 8.2[0-34]$

Retrospective $1993-2005 \quad 170 \quad 25[0-61]$

Retrospective $1993-2003 \quad 153 \quad 28[0-65]$

Retrospective $1993-2003 \quad 81 \quad 21[0-51]$

Retrospective $1989-2002 \quad 119 \quad 31[5-56]$

Retrospective $1996-2003 \quad 38 \quad 13[1-30]$

Retrospective $1991-2002 \quad 60 \quad 15[0.5-67]$

Retrospective $1986-2000 \quad 399 \quad 23[0-59]$

Prospective $1991-2002 \quad 169 \quad 30[0-54]$

Concha 2003 (39), Eur $J$ Cardiothorac Surg

Root/reinforced root/non reinforced

Root/l//subcoronary

Root

Root/lC/subcoronary

Root/subcoronary

Root/subcoronary

Root/IC

Root/lC

Root/IC/subcoronary

Root/RK

Root/RK

Root

Root

Root

Root

Subcoronary/lC

Root/l//subcoronary

Root

Root/l//subcoronary

Root/subcoronary

Root/RK

Root

Root/subcoronary

Root/subcoronary

Subcoronary

Subcoronary

Subcoronary

$\begin{array}{llllllll}8.3 & 1.0(0.6-1.5) & 3.03(2.8-3.2) & 0.69(0.65-1.31) & 0.62(0.58-1.24) & 0.22 & 0.36 & 0.08(0.03-0.50)\end{array}$

$\begin{array}{lllllll}1.3(0.7-1.6) & 3.20(2.9-3.6) & 0.74(0.70-1.42) & 0.62(0.60-1.30) & 0.26 & 0.42 & 0.11(0.05-0.54)\end{array}$

$\begin{array}{lllllll}2.7(1.31-5.98) & 5(3.0-7.0) & 0.46(0.41-1.20) & 0.46(0.41-1.20) & 0.06(0.00-0.56) & 0.23(0.17-0.85) & 0.12(0.06-0.66)\end{array}$

$2.5(1.25-4.40) \quad 4(2.0-6.0) \quad 0.44(0.39-1.18) \quad 0.44(0.39-1.18) \quad 0.04(0.00-0.48) \quad 0.22(0.15-0.70) \quad 0.10(0.04-0.60)$

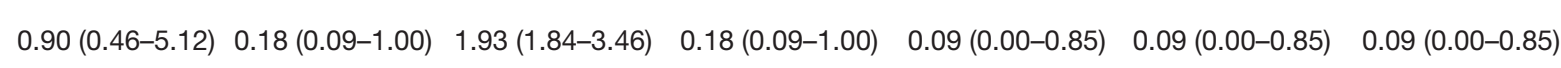
$2.70(2.40-7.08) \quad 0.32(0.28-0.82) \quad 1.81(1.77-2.72) \quad 0.63(0.59-1.25) \quad 0.08(0.04-0.45) \quad 0.16(0.12-0.58) \quad 0.04(0.00-0.38)$ $\begin{array}{lllllll}3.9(2.50-7.30) & 0.33(0.30-0.90) & 1.92(1.85-2.90) & 0.80(0.75-1.80) & 0.10(0.06-0.45) & 0.16(0.12-0.58) & 0.06(0.01-0.40)\end{array}$ $\begin{array}{lllllll}2.80(2.50-7.15) & 0.35(0.32-0.90) & 1.90(1.80-2.82) & 0.75(0.62-1.32) & 0.10(0.10-0.80) & 0.20(0.16-0.65) & 0.08(0.00-0.40)\end{array}$ $2.70(2.40-7.08) \quad 0.32(0.28-0.82) \quad 1.81(1.77-2.72) \quad 0.63(0.59-1.25) \quad 0.08(0.04-0.45) \quad 0.16(0.12-0.58) \quad 0.04(0.00-0.38)$ $1.80(1.60-4.72) \quad 0.10(0.05-0.58) \quad 0.10(0.05-0.58) \quad 0.05(0.00-0.50) \quad 0.05(0.00-0.50) \quad 0.05(0.00-0.50) \quad 0.05(0.00-0.50)$

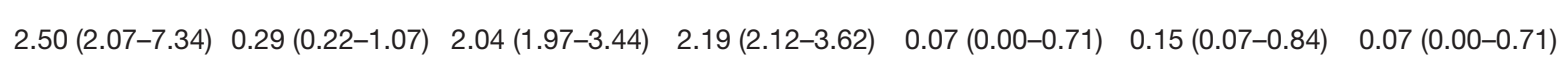
$1.20(0.90-4.40) \quad 0.12(0.06-0.67) \quad 1.41(1.35-2.47) \quad 0.82(0.76-1.70)$

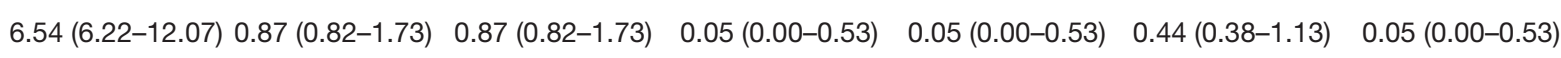

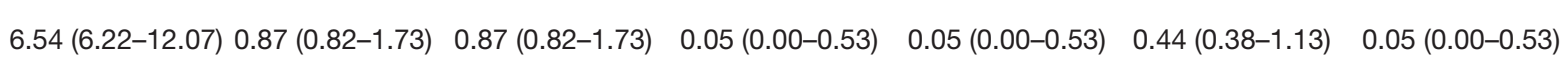
$\begin{array}{lllllll}1.70(1.27-6.18) & 0.37(0.28-1.37) & 2.05(1.96-3.68 & 0.75(0.65-1.93) & 0.19(0.10-1.07) & 0.09(0.00-0.91) & 0.09(0.00-0.91)\end{array}$ $2.60(1.34-15.08) 0.94(0.48-5.41) \quad 0.47(0.00-4.59) \quad 0.47(0.00-4.59) \quad 0.47(0.00-4.59) \quad 0.47(0.00-4.59) \quad 0.47(0.00-4.59)$ $0.80(0.02-8.10) \quad 0.14(0.00-1.40) \quad 0.86(0.72-2.55) \quad 0.14(0.00-1.40) \quad 0.14(0.00-1.40) \quad 0.29(0.15-1.65) \quad 0.57(0.43-2.11)$ $3.50(3.39-5.90) \quad 0.29(0.26-0.69) \quad 1.28(1.26-1.95) \quad 0.93(0.91-1.52)$

$2.40(2.08-6.12) \quad 0.46(0.35-1.71) \quad 1.16(1.05-2.73) \quad 0.70(0.58-2.06) \quad 0.12(0.00-1.13) \quad 0.70(0.58-2.06) \quad 0.46(0.35-1.71)$ $\begin{array}{lllllll}2.60(2.44-4.93) & 0.58(0.54-1.14) & 1.01(0.97-1.70) & 0.58(0.54-1.14) & 0.22(0.18-0.64) & 0.04(0.00-0.35) & 0.07(0.04-0.41)\end{array}$ $2.70(2.26-8.00) \quad 0.75(0.63-2.22) \quad 2.00(1.88-3.96) \quad 0.75(0.63-2.22)$

$0.70(0.01-6.75) \quad 0.23(0.00-2.25) \quad 3.24(3.01-6.71) \quad 0.23(0.00-2.25)$

$1.25(0.03-12.15) 1.25(0.03-12.15) 1.25(0.03-12.15) 1.25(0.03-12.15)$

$2.80(2.30-8.15) \quad 0.17(0.00-1.68) \quad 0.69(0.52-2.55) \quad 0.17(0.00-1.68) \quad 0.17(0.00-1.68) \quad 0.17(0.00-1.68) \quad 0.69(0.52-2.55)$ $2.20(2.10-5.08) \quad 0.29(0.27-0.70) \quad 1.81(1.77-2.72) \quad 0.63(0.59-1.25) \quad 0.08(0.04-0.45) \quad 0.16(0.12-0.58) \quad 0.04(0.00-0.38)$ $6.6(3.39-9.90) \quad 1.7(0.05-13.50) \quad 2.04(1.97-3.44) \quad 2.19(2.12-3.62)$

$\begin{array}{lrrr}\text { Retrospective } & 1967-1986 & 241 & {[9-60]} \\ \text { Retrospective } & 1967-1977 & 188 & 30[9-64]\end{array}$ Retrospective $1967-1972 \quad 85 \quad 30[12-54]$

$2.20(2.10-5.08) \quad 0.30(0.24-0.80) \quad 1.81(1.77-2.72) \quad 0.63(0.59-1.25) \quad 0.08(0.04-0.45) \quad 0.16(0.12-0.58) \quad 0.04(0.00-0.38)$ $2.20(2.10-5.08) \quad 0.30(0.24-0.80) \quad 1.81(1.77-2.72) \quad 0.63(0.59-1.25) \quad 0.08(0.04-0.45) \quad 0.16(0.12-0.58) \quad 0.04(0.00-0.38)$

30 [12-54] Subcoronary

8 fructural valvular deterioration; RVOT, right ventricular outflow tract; $\mathrm{TE}$, thromboembolism; $\mathrm{BL}$, bleeding; $\mathrm{VT}$, valve thrombosis. 


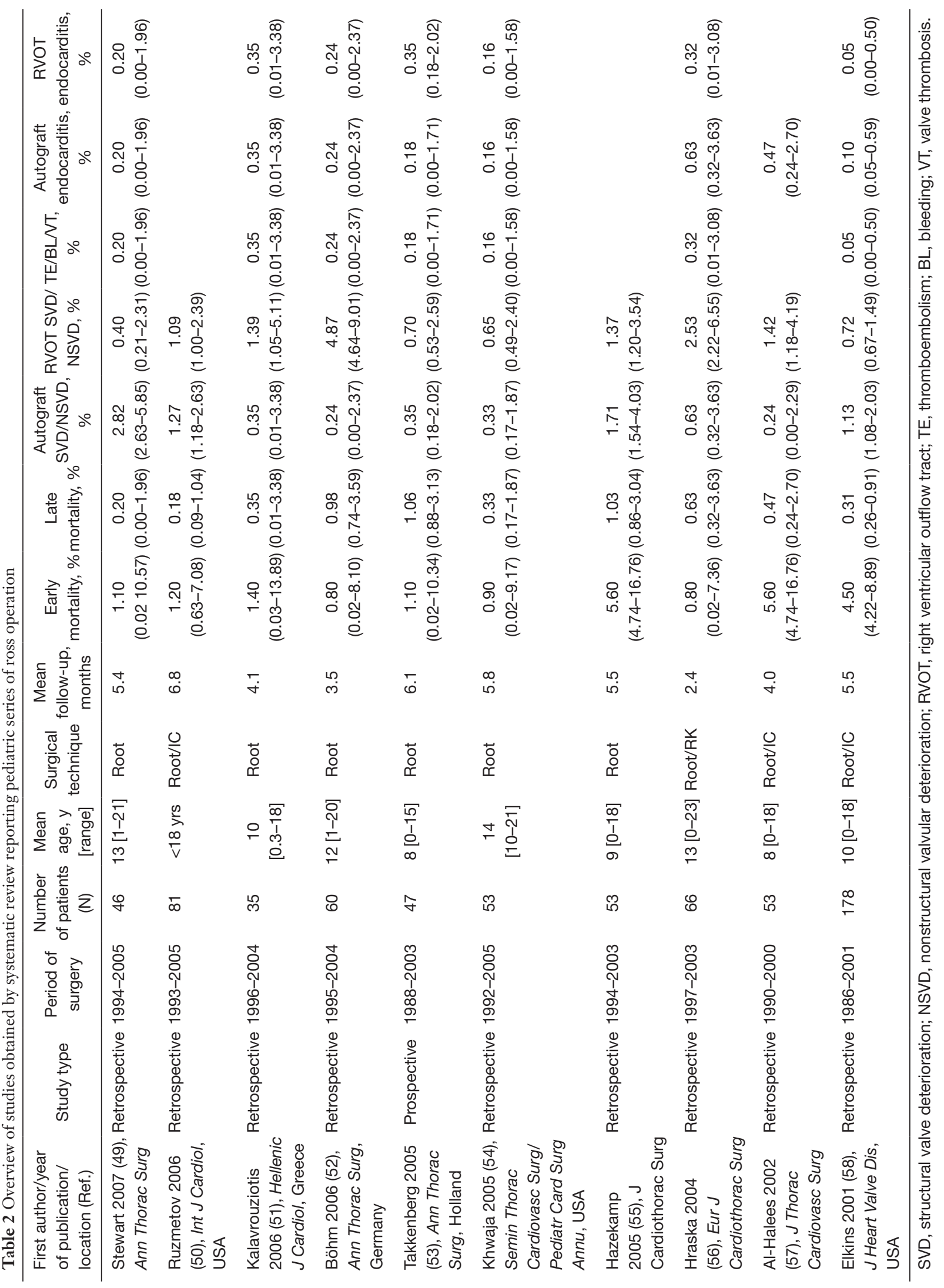


several institutions worldwide. Late rates were remarkably low alongside similar age-matched mortality with the general population in young adults (as per Table 1) (13,59). Evidence suggests that the survival benefit, which is widely recorded in children and young adults, is related to the use of the PA over other substitutes (mechanical or biological) to treat aortic valve disease in this age range (60-66). In fact, the advantages of avoidance of lifelong anticoagulant treatment, better haemodynamics features of the PA and its increase in sizing that matches somatic growth are remarkably significant. The living tissue (PA) undergoes favourable remodelling when translated into the aortic position as clearly demonstrated in several biomechanical studies $(13,21-24,58,59,67)$. In addition, concerns regarding the occurrence of thromboembolic events, major bleeding, nonstructural valve deterioration and endocarditis is significantly reduced compared to other aortic valve replacements (64).

The Achilles heel of the Ross Procedure is the finite durability of the PA and the cryopreserved pulmonary homograft (P-Ho) leading to reoperation for structural valve deterioration, which is required for both the $\mathrm{PA}$ and the P-Ho used for the reconstruction of RVOT. These are undoubtedly the most common valve complications recorded in the two-valve substitutes. The trend regarding reoperation for structural/nonstructural degeneration of the pulmonary homograft used for the restoration of RVOT is inconsistent, thus causing an increasing variability in the reported freedom from reoperation limited to the first postoperative decade $(7-9,65,66,68)$.

\section{Publication bias and subgroup analyses}

The study design that was performed aimed to avoid heterogeneity of causes, but a trend towards higher outcome estimates was noted in small studies. Therefore, two categories of patients were selected: studies with a mean patient age below 18 years $(\mathrm{n}=10)$ (Table 2) versus studies with a mean patient age above 18 years $(n=30)$ (Table 1$)$. Outcomes of retrospective and prospective studies of such population ( $>$ or $<18 \mathrm{yrs}$ ) have been combined. For studies with a mean patient age below 18 years compared to studies with a mean patient age above 18 years, the structural/ non-structural valvular deterioration rates of autograft and RVOT were $1.18 \%$ [ $95 \%$ confidence interval (CI), $0.85 \%$ to $1.59 \%$ ] versus $1.73 \%$ (95\% CI, $1.04 \%$ to $2.81 \%$ ) and $0.68 \%$ (95\% CI, $0.42 \%$ to $1.04 \%$ ) versus $1.69 \% /$ patientyear (95\% CI, $0.99 \%$ to $2.84 \%$ ), respectively. The duration of the follow-up did not affect the study results. Risk of bias arising from missing results was addressed by the direct exclusion of studies which did not report results and measures we were interested in. To assess confidence for outcomes we only selected studies with authors including an expert in statistics and set confidence levels at $95 \%, \mathrm{P}$ values threshold at 0.05 and similar statistical powers to our previous studies.

\section{Discussion}

\section{Specific characteristics of the population}

The evidence relating to the individual baseline characteristics of the patient suggests that some factors such as patient age, presence of aortic regurgitation (related to the pathogenesis of valvular disease), and aortic dilatation are determining elements that affect the longevity of the PA. Luciani et al. (26) reported greater PA dilation in younger patients without associated late autograft dysfunction. We recorded a mean annual expansion of autograft that was $0.15,0.30$ and $0.40 \mathrm{~mm}$ for the aortic annulus, Sinus of Valsalva and sinotubular junction (STJ) using PA not exceeding $35 \mathrm{~mm}$ in length $(4,24)$. Hörer noted that during the growth phase of neoaortic root in children, limiting the conduit length to $35 \mathrm{~mm}$ might be useful to prevent PA dilation $(69,70)$.

Given the results from this review, the younger patient age may correlate with decreased autograft durability (31). We need to accumulate more evidence on the performance of the PA in the second decade after procedure to establish whether the patient's age is truly a determining factor in the duration of the PA. However, we know that Sievers et al. reported $90 \%$ freedom from PA reintervention in adult patients who received subcoronary PA implantation (71).

David et al. suggested a direct implication of congenital aortic valve disease with the risk of dilation of the PA implanted as a miniroot (72). Settepani et al., in a series of Ross procedures used in the adult population, reported a possible association between the anatomical functional disorder of the bicuspid aortic valve type and an increase in PA dilation with increased occurrence of aortic regurgitation (73). In our analysis there was no data to confirm this trend towards an increase in the diameter of the neoaortic root in patients with congenital bicuspid aortic valves (22).

However, no conclusive evidence emerged from a prospective study, which was designed to obtain serial echocardiographic evaluation to demonstrate a specific 
correlation between congenital aortic valve disease and increased risk of PA failure in the first decade after insertion. The current understanding does not seem to directly correlate bicuspid valve disease with early PA dysfunction, so a restriction of the indication to use PA remains a point of discussion (73).

Kumar et al. reported a large consecutive series of patients, including children, young adults and adults, who were managed using PA to treat rheumatic aortic valve disease $(33,34)$. The authors recorded a reduced durability of PA possibly attributable to a higher recurrence rate of rheumatic fever, with greater involvement of the valve constituting the pulmonary miniroot in children compared to the adult population. A resurgence of streptococcal infection when not controlled by adequate prophylactic antibiotic therapy could be one of the causes of early PA dysfunction observed in the juvenile population (26,33-35).

Connective tissue disorders involving the LVOT and aortic valve, sustained by preoperative aortic valve regurgitation, can lead to early PA failure (9). Several reports, which evaluated the follow up of the PA implanted in pediatric and adult patient populations, focused on the combination of preoperative aortic insufficiency and PA dysfunction (41,57). The studies by Laudito et al. (42) and Elkins et al. (11) consider annular dilation to be associated with an increased risk of neoaortic root regurgitation which can be related to a structural deficiency of the subvalvular ventricular tissue and the aortic annulus. Chronic transaortic regurgitation is suggestive of prolonged damage on the LVOT geometry that does not recover after PA implantation. Morphofunctional features of the ascending aorta were investigated by Luciani et al. who checked 90 patients aged 6 to 49 years. They found that patients in whom the aortic root had increased preoperatively had subsequently predicted autograft dilation. Patients with a morphofunctional disorder of the aortic root have unfavourable evolution so resection of the dilated aorta is recommended rather than choosing conservative surgery of the ascending aorta to prevent dilation (26).

A pulmonary homograft was used in the patients reported in this review to reconstitute the ventriculo-pulmonary junction anatomy (RVOT). Only a smaller number of patients were managed with the use of a bioprosthesis and more commonly a bovine jugular vein conduit was implanted. We recorded a higher rate of structural and nonstructural degeneration in the younger than the adult population with the use of the biological prosthesis inserted as a component of the RVOT. Concern related to the degeneration of the restored RVOT is the growth/size heterogeneity of the conduit that needs to be considered in young children, which may herald issues with mismatch related to the higher body surface area to the implanted valve substitute $(65,66,74,75)$. To ensure the integrity of the pulmonary homograft and prevent the immune response, anti-inflammatory drugs have been used with good results.

Much promise is expected from tissue bioengineering research focused on decellularized substitutes (DAVA). These derivatives have recently been used as an alternative to allogeneic tissues with favourable results especially due to the weak inflammatory response they generate (76-78).

\section{What procedure to be used during the growing years and adolescents}

Concerns about the different outcomes after using the PA in the Ross procedure may be due, at least in part, to the variation in surgical handling for the PA implantation. Our report reveals that most patients with a PA for the Ross procedure received the full root replacement technique, named the miniroot technique, involving coronary artery reimplantation. Individual variations of the miniroot technique have been reported and may account for these differences.

The implantation of the PA using the subcoronary technique, primarily described by Ross, has been progressively abandoned by many surgeons because of the greater technical complexity alongside poor adaptation to somatic growth in recipients of the Ross procedure. In fact, the use of the subcoronary implant and insertion of the PA with the technique of the inclusion cylinder can be suitably performed after the age of 16 which largely corresponds to the end of somatic growth $(21,79,80)$.

The best results using subcoronary insertion were recorded by Sievers et al. who have considerable experience with Ross procedures and different PA implantation techniques. The authors described 630 consecutive patients in which the PA valve performance was evaluated after the use of the subcoronary Ross procedure $(71,81)$. The median follow-up was 12.5 years (maximum 22.3 years with 7,404 patient-years and $99.4 \%$ of completeness); a unique aspect of the statistical analysis was that the long-term survival of operated patients was compared with age- and gendermatched German general population data. It is important to note that only a few of the patients $(3.2 \%)$ were $<20$ years and received the subcoronary implantation (71).

The valve performance classification has assembled 
hemodynamics, symptoms, and management criteria. Four classes were included: class I (normal/near normal), class II (mild dysfunction), class III (moderate dysfunction), and class IV (severe dysfunction). The investigators reported a twenty-year post-operative survival of $73.1 \%$ [95\% confidence interval (CI), 65.4-81.6\%] and highlighting statistical noninferiority from the age and gender-matched general population; freedom from reoperation was $85.9 \%$ (95\% CI, 80.2-92.0\%; $0.6 \%$ per patient-year), $89.8 \%$ (95\% CI, 84.3-95.7\%) for autograft, and 91.0\% (95\% CI, $86.3-96.0 \%)$ for homograft used for the reconstruction of LVOT. At 20 years the probability of a patient being in valve performance class I to IV was 5\%, 74\%, 19\%, and 1\%, respectively (71).

These data confirmed the results of the same group (German-Dutch Ross registry) which revealed that the leading cause of autograft valve failure with the need for reoperation in the subcoronary group was structural valve deterioration ( $80 \%$ of all reoperations), due to cusp prolapse (69\% of all structural valve deteriorations) $(12,15)$. It should be highlighted that the results recorded by Sievers et al. are indisputably excellent and provide ambition for surgeons who are ready and competent to employ this technique.

The use of the full root replacement Ross procedure, described in the 90s by the Oklahoma group (11), was considered an attractive option because the replacement of the aortic root allows preserving both the geometry of the valve of the preserved entire apparatus (valve, valsalva sinuses, aortic root), and the mechanics of the ventricularaortic junction. The miniroot technique was recommended during the somatic growth phase. In addition, full root replacement handling is required in many circumstances related to the morphology of the valve, etiology, and unique features of the aortic and pulmonary root. Concerns are related to the fact that the aortic and pulmonary roots often have different dimensions and commissural distribution as noted in patients with aortic regurgitation and/or bicuspid/ unicuspid aortic valves. In these patients, the use of the subcoronary implantation is suboptimal $(5,11,14,22)$.

This miniroot procedure can be performed in multiple ways. The insertion of the PA above or below the annulus is the one that has sparked controversy. During the handling of proximal anastomosis, best outcomes are noted when bringing the inferior suture through the area adjacent to the leaflet attachment and not into the muscle rim of the right ventricular outflow tract. This minimizes the risk of a reduced vascularization of the right ventricle thus preserving against possible necrotic evolution and dilation due to devascularized nonstructural support. The proximal suture line can be performed with the continuous or interrupted technique. It can be reinforced with pericardial strips which are useful in the annulus of patients who experience annular dilation and/or aortic insufficiency. In the event the surgeon chooses to use pericardial reinforcement, three semicontinuous sutures (for each commissure) are preferable to simplify the implantation of the PA $(72,82,83)$.

Another point of concern is the length of the neoaortic root which can be variable. Some surgeons prefer to implant shorter PA roots and avoid going beyond the sinotubular junction while others use the full extension of the PA root. This point of discussion is very important because it is central to preventing early PA dysfunction as highlighted in some series of children and young adults. The most effective results have been achieved with the use of a short segment of PA-root implants, below the annulus, which is less subjected to the stress exerted by the systemic pressure. It is important to note that the use of located supra-annular PA root is not associated with the development of early PA failure. Several studies suggested that the progressive dilation of the neoaortic root occurs first at the level of the sinotubular junction and then in the segments corresponding to the annulus and the Valsalva sinuses. Therefore, it seems evident that minimizing the length of the PA, containing it within the limits of the STjunction, may lead to less risk of dilation. The PA may be inserted with the use of the inclusion cylinder technique. In our review, we recorded a low number of patients who benefited from this procedure $(2-4,13,14,44)$.

Although the Ross cylinder is effective in preventing dilatation of the neoaortic root, $(52,82,83)$, however, the procedure is suitable in patients without anatomical issues of the ascending aorta and aortic root. In addition, the Ross cylinder technique possibly raises technical concerns related to distortion of the reimplanted coronary arteries (84).

Evidence suggests that homogeneity between the ascending aorta and the size of the PA root at the outflow anastomosis is a determining factor for the long duration of the Ross procedure. For this reason, performing a distal anastomosis by equalizing the dimensions of the PA and aorta using a polypropylene 5-0 or polypropylene 6-0 for newborns is recommended. The PA is trimmed $3 \mathrm{~mm}$ above the top of the commissures of the PA and the excess ascending aorta removed to create two compatible suture surfaces at the anastomotic site. More recently, the use of an external reinforcement of the PA with a prosthetic Dacron graft or semi-resorbable scaffold has been proposed to 
prevent late dilatation and dysfunction $(22,72,82,83,85,86)$. However, we are unaware of long-term results from randomized/non-randomized controlled trials that support the effectiveness of these approaches.

\section{Biological and histological facets}

\section{Surgeon and biological aspects}

Given its structural complexity, the aortic root has a refined conformation collected in four leading parts: the aortic annulus, the aortic leaflets, the sinuses of Valsalva, and the sinotubular junction. The use of the PA as a full root replacement exposes the entire structure of PA to the stress exerted by systemic pressures, potentially leading to late PA expansion. The detrimental effects of pressure stressors materialize variably on the four components, with different morphological and functional effects. The structural anomalies are accompanied by histological and biological changes. For example, connective tissue disorders affecting the aortic annulus, often found with size $(>26 \mathrm{~mm})$ and are accompanied by severe aortic regurgitation, can cause the failure of the Ross procedure with subsequent late PA dysfunction $(9,82)$.

In these cases, the surgeon is called upon to deal with a complex biological phenomenon. Reducing the size of the aortic ring by performing a plication with the suture can mitigate early dilation $(72,83)$, but late failure remains inevitable (80). The structural failure of the annulus can only be resolved by providing a solid external scaffolding. Therefore, the systematic execution of an extra-aortic annuloplasty, using a circular ring of Dacron as a rigid support, may be more effective in reducing the risk of late annular dilation (87). To date we are not aware of the effectiveness of the use of these alternative approaches to circumvent the biological issues with longer follow-up is required for confirmation.

The same problem occurs in patients with progressive structural disturbance of the native aortic wall, potentially susceptible to dilatation. The implanted PA may dilate at the level of the sinotubular junction, leading to PA failure. Therefore, some external supports are advocated to mitigate the risk of aortic dilatation and are aimed as a protective action on the neoaortic root. As for the external supports, surgeons may use non-absorbable reinforcements such as Dacron $(72,83,88-91)$ or semi-absorbable scaffolds $(85,86,88,92)$ that fully respect the biological characteristics of the living tissues characterizing the PA. Since the dilation is more frequently located at the level of the sinotubular junction, the external dacron supports may be limited to this part of the neoaortic root $(87,89-91)$.

Evidence suggests that the increased diameter of ascending aorta with a size $>38$ to $40 \mathrm{~mm}$ is considered a critical measurement reference for PA dysfunction. In this context, the work of Hörer et al. (70) detailing the kinetics of PA dilation during the growth phase is noteworthy. The investigators found a significant expansion at the level of the neoaortic sinus $(0.5 \pm 0.1 /$ year, $\mathrm{P}<0.001)$ and the sinotubular junction $(0.7 \pm 0.2, \mathrm{P}<0.001)$, but not at the level of the annulus $(0.1 \pm 0.1, \mathrm{P}=0.59)$ at a mean follow-up of 5.1 years. We recorded that the mean annual dilatation of neoaortic root was $0.15,0.30$, and $0.40 \mathrm{~mm}$ for the aortic annulus, sinus of Valsalva and sinotubular junction (STJ), respectively, which was inferior to that observed by Hörer in children who were managed with the use of PA implanted as full root replacement during the growth phase. These findings suggest considering different facets; surgical, biological and mechanical, that limit the risk of PA expansion and failure. We consider maintaining the conduit length at $35 \mathrm{~mm}$ to be useful in preventing PA dilation due to specific biomechanical features $(2-4,21)$.

\section{Histology of $P A$}

We induced remodelling of the PA reinforced with a bioabsorbable mesh of polydioxanone by recording a normal thickness of PA implanted under a systemic pressure regime. From a histological point of view, we noticed intimal hyperplasia within the tunica media that was perfectly intact although the remains of some fragments of PDS, characterized by a slow process of reabsorption were detectable at the level of the adventitia. Utilizing Masson's trichrome stain (Sigma-Aldrich, St. Louis, MO, USA), we highlighted the preservation of the endothelium and reorganization of the tunica media. In particular, the integrity of the PA was represented by smooth muscle cells which were intertwined with collagen fibers and directly under the tunica intima; deeper, the collagen bundles were intertwined with elastic fibers, which formed a dense and highly organized layer of concentric lamellae. This histological evidence suggested that resorbable polymers such as PDS and PLLA lead to the development of elastic remodelling of the PA wall $(86,88,92-98)$.

Different aspects should be considered when planning a Ross procedure for patients in the growing phase or in those that have completed their somatic growth. The survival 
benefits associated with using the PA for the aortic valve replacement in patients who had completed the somatic growth were established in a landmark paper from National Heart and Lung Institute, Royal Brompton and Hartfield Hospitals. Twenty years ago, Carr-White et al. supported this finding by evaluating mechanics and morphological structures in patients who were randomized to undergo aortic valve replacement with an aortic homograft $(\mathrm{n}=37) v s$. PA (n=49) (99).

The authors additionally studied structural and functional changes in the implanted autograft of 18 patients at the end of somatic growth who underwent PA surgery (maximum follow-up $=4$ years) and compared it to the aortas of 8 normal age-matched organ donors. The authors reported no significant progressive dilatation of the aortic root in either the homograft or the PA. Dilation of the aortic root at any level $>20 \%$ (annulus, sinotubular junction, and Valsalva sinuses) was not found in patients of either group and none of them had more than mild aortic regurgitation. However, differences in the anatomic structure and mechanical behavior of the PA in vitro were evident. The tunica media of the PA tended to be thicker in the autograft group. The elastic fiber components in all patients receiving an aortic homograft showed minimal or no change, while in those who had PA, considerable variation in fragmentation was evident. However, despite the differences in net stiffness, higher stiffness modulus, and maximum tensile strength, the PA explanted after only 4 months appeared to show adaptation in mechanical behaviour (99).

Rabkin-Aikawa et al. evaluated the difference between histological changes in PA occurring in the valve and the conduit wall. Investigators noted that explanted PAs were viable with preserved trilaminar leaflets structure and nearly normal collagen architecture. Instead, the PA wall was damaged, with localized depletion of normal smooth muscle cells, elastin, and collagen (100). Schoof et al. performed a very thorough histological analysis comparing the explanted PA with native pulmonary and aortic valves. The histology has shown that unlike a normal morphostructure of the pulmonary and aortic valves maintained in place and subjected to physiological stress conditions, the explanted valves of the PA while retaining an intact laminar architecture and cellularity, nevertheless show apposition of fibrous tissue on the ventricular size (101). These pulmonary valves implanted in the aortic position had an overall increased thickness, a morphological condition very similar to that which occurs in an aortic regurgitation that persists for a long time. The autograft wall revealed a typical and severe lack of consistency leading to aneurysm formation, intimal hyperplasia, and degeneration of the tunica media. The latter was characterized by fragmentation with lack of elastin and hypertrophy of smooth muscle cells. In addition, adventitial fibrosis can lead to functional reactive neovascularization with the formation of vasa vasorum (101).

\section{Biology of PA}

The biological mechanisms sustaining the morphological modifications responsible for PA expansion are still not fully perceived. The field of biology and proteomics can be a promising and interesting research tool for further development of our knowledge. Evidence has shown that PA endothelial cells implanted in the aortic position can express EphrinB2 which is a typical marker of the left sided chambers, but not found in the endothelium of the valve components of the right heart. It has been hypothesized that an increase in EphrinB2 expression leads to a remodelling of the extracellular matrix with increased actin production of smooth muscle (100).

The mechanisms underlying the adaptation process of the valvular leaflets of the PA located on a systemic pressure regimen after aortic replacement are consequent to the new mechanical stressors to which the PA is subjected. Therefore, the longevity of the valve leaflets will depend on the reversible phenotypic changes induced by the new environment and on the ability of the PA to adopt similar characteristics of the leaflets and conduit of the normal aorta. It is evident that increased leaflet thickness and breaking strain allowed the PA to become almost identical to the native aorta valve leaflets, increasing the possibility of the PA to retain its integrity over time (102).

We have reported the same adaptive mechanism at the level of the PA wall using resorbable polymeric supports that have shown the possibility of enhancing this PA remodelling capacity $(85,86,88)$. A complex vascular remodelling process was induced through the interaction between a bioabsorbable reinforcement and the PA. This process was driven by a balance between inflammation and extracellular matrix (ECM) production which led to the generation of a "new vessel" at the end of the biomaterial reabsorption process (103-106). The structure generated revealed characteristics similar to those of the aorta but was still biologically alive and able to grow. Histological analysis of the ECM showed that these reinforced PAs 
contained more elastin fibers in the PA and had a denser organization of collagen fibers in the elastic zone of the vessel. From a molecular point of view, it is interesting to note that the metalloprotease MMP-9 and the Ki 67 were overexpressed confirming ongoing matrix remodeling. At the same time, increased cell proliferation was noted with a concomitant reduction in the rate of apoptosis, further supporting the idea of active cell remodeling and growth (103-106). Further studies on the use of a semiresorbable reinforcement composed of polydioxanone and expanded polytetrafluoroethylene mesh have shown promising results especially in attenuating the effect of systemic loading pressures immediately post-implantation $(85,105)$.

Chiarini et al. suggested a maladaptive remodeling process occurring in nonreinforced PA during the dilatation process. The authors evaluated the molecular change, based on specific proteomic features, that were developed in the tunica media of dilated PA compared to the usual pulmonary artery and aorta tissue. The molecular modification observed and significantly characterized by an upregulation occurred in the unreinforced and expanded PA including some proteins responsible for the specific function of the vessel wall (103). Specifically, the authors recorded the down-regulation for genes encoding proteins related to focal adhesion (e.g., paxillin) and the cytoskeleton (e.g., vimentin). In addition, there was downregulation of genes for proteoglycans that regulate metalloprotease functions (e.g., testican-2). A significant reduction was observed in the concentration of microfibril-associated glycoprotein 1, which determines the levels of elastic fibers in the tunica media. The investigators noted significant changes in specific proteins leading to the regulation of cellular signaling including an increase in levels of the soluble Jagged-1 fragment and of the ectodisplasin-2 receptor, and a decrease of Notch-1 intracellular domain fragment. The major finding of this investigation was the significant variation in the levels of structural proteins necessary to maintain the integrity of the vascular wall. A marked difference of absolute levels of Paxillin, Vimentin, Jagged-1 fragment, and Notch1 intracellular domain fragments were noted when comparing the PA to those of aortic controls (103).

The results reported by Chiarini et al. focused on maladaptive remodeling of non-reinforced PAs paved the way to drastically consider the use of PA reinforced with synthetic or biocompatible materials $(103,104)$. We are unaware of any studies comparing proteomic changes. The latter is more compatible with the biological and mechanical characteristics of PA implanted in the aortic position and subjected to a regime of systemic pressures as documented by our group by analyzing the significant biological and tissue remodelling (104-107).

\section{Future direction: considering biomechanics in growing PAs}

Carr-White $e t$ al. reported that the absence of progressive dilatation of the aortic root was due to the variations in surgical technique, particularly involving the proximal and distal suture line, as well as the orientation of the autograft and the sizing match of the two vessels at the site of anastomosis (99). Of note, the percentage of patients who underwent the Ross operation for congenital bicuspid aortic valve disease was small and the follow-up was only around 3 years. It is difficult to predict if the expansion of the aortic root in this subtype of patients could have been significantly more important if longer follow-up and a larger number of patients were taken into consideration (82).

Given these preliminary results, we evaluated the biomechanical properties of leaflets and arterial roots of the PA and native aorta regarding circumferential and longitudinal stresses, to which the PA is subjected after transposition in an aortic position and increased pressure stress. Our findings agree with the previous study of CarrWhite et al. regarding the mechanical behaviour of the PA after the functional biaxial stress test $(11,105,106)$ and expand on the previous report by Hörer et al., marking a definitive point concerning the non-linear behavior between growth, remodeling, and shielding stress of PA exposed to systemic pressures $(59,69,70)$.

The importance of the biomechanical features of PA in the context of growth, remodeling, and shielding stress $(103,104,106)$ has been confirmed by Mookhoek et al. who found that the nonlinear response to mechanical load in failed PAs, but contemporaneously demonstrated increased compliance and reduced wall stiffness of the PA when compared to the native pulmonary artery, suggesting an explanation for PA dilation (108). In another study by the same group comparing failed PA root to the native aorta, these Authors demonstrated increased compliance of explanted PA roots in respect to the aorta, but their inadequate biomechanical remodeling, which did not match the characteristics of wall stiffness properties of native aorta (109).

We recorded the importance of the remodeling phenomena occurring in the PA and its reflexes on the biomechanical properties of the remodeled autograft using 
an in vivo model of the Ross operation and also reported the stress shielding effects that a resorbable mesh may exert when applied as a reinforcement for the PA $(85,88,105,106)$. In other reports, we previously demonstrated that Dacron grafts and other synthetic polyesters severely impair aortic compliance when used as external pulmonary artery reinforcement and elicit a strong inflammatory reaction with significant damage to the vessel wall and negative stress shielding effects on the distal suture (104). Conversely, we focused our research efforts to the development of a resorbable reinforcement based on polydioxanone and showed morpho-structural and histological remodeling of the PA reinforced with this material after implantation in an animal model of the Ross Operation $(85,86,88)$.

Using finite element analysis simulation (FEA), we demonstrated that the interaction between the material properties of the autologous graft and the aorta, the suture regions, the geometry and dilation constraints imposed by the annulus were crucial for determining the effects of actual stress concentrations, the occurrence of deformation localization and deformation gradients. All these variables represent the success of the Ross operation $(22,110)$.

Evidence based on the biomechanical study suggested other important parameters regarding the difference in circumferential and longitudinal stress-bearing abilities of the aorta and the PA and the topographical differences of the biomechanical properties among the components of the aortic root. Indeed, while the aorta revealed a consensual increase in stress and deformation in both directions, the pulmonary showed better adaptability in the longitudinal direction and a steeper curve in the circumferential response, suggesting the ability of the PA to evenly absorb mechanical stresses and potentially explaining its known dilatation tendency over time. Secondly, a higher degree of resistance to deformation of the valve leaflets with a stiffer behavior in respect to the aorta for applied loads of about $240 \mathrm{kPa}(1,800 \mathrm{mmHg})$ was demonstrated (22). The significant physiological pressure value considered for the analyses was $80 \mathrm{mmHg}$, as also reported by Mookhoek et al., the FE were conducted in static regimes, thus neglecting inertia effects, and standard convergence algorithms were also used to follow the nonlinear procedure related to the presence of both large deformations and hyperelastic behaviour $(108,109)$. The results for the different thicknesses $(2-2.5 \mathrm{~mm})$ showed that the circumferential stress peaks were found in the range $118-158 \mathrm{kPa}$ for aorta roots and $206-277 \mathrm{kPa}$ for native $\mathrm{PA}$, in line with those obtained by Mookhoek et al. in their simulations $(108,109)$.
Similar comparisons can be made in terms of deformed thicknesses and diameters, where the major discrepancies are registered with respect to the PA. Importantly, this difference can be traced in the mechanical properties of the vessels, and in the study, we reported that it was relative to the native PA (PA implanted before degeneration due to the effect of expansive systemic load). Unlike Mookhoek et al., the PA autografts used were already degenerating. Based on the simulations, replacement of the native aorta with PA root was predicted to induce an instantaneous elastic increase in vessel diameter of approximately $32-33 \%$, associated with a corresponding decrease in thickness of approximately $23-24 \%$ (22).

For patients in the growth phase, the implantation of the PA as mini-root at the level of the sinutubular junction, and therefore with a smaller surface subjected to the stress of systemic pressure, needs to be guided by the characteristics of the aorta growth process itself. It is important to remember that in childhood (ages 1-6 years) the aortic annulus and the sinutubular junction have the same diameter and index/ratio $=1$, thus the aortic root could be considered a regular growing cylinder. More evidence is needed on the remodeling process of PA during somatic growth compared to a fully defined evolutionary one $(22,111,112)$.

\section{Clinical application}

We could draw the following conclusions and trace new avenues of future investigation in the field of the Ross procedure. Firstly, we demonstrated how proper descriptions of both boundary conditions (the presence of the suture region and the constraints of the annulus) and the nonlinear response of the vessels are crucial for determining actual stress and the dimensional expansion of the PA structures and how this dilatation phenomenon relates to the age of implant of the PA, giving attention to the phase of the somatic growth of the patient. In this context, our findings employ a further analysis of the observations previously described by Hörer et al. (70) regarding the yearly diameter increase of the annulus, Valsalva sinus, and sinotubular junction of the PA. Secondly, the length of the conduit to be implanted and the technique of implantation need to be specifically tailored (22).

When translating these considerations into clinical practice, the age of implant in the period of somatic growth (before and after six years) plays a crucial role in this context. Importantly, before six years of age there is 
no difference in size between the annulus, Valsalva sinus and sinotubular junction and the PA can be considered as a cylinder with homogeneous size and the miniroot technique of implantation appears to be the most appropriate in these cases $(22,112)$. After six years of age three different dimensions, annulus, Valsalva sinuses, and sinotubular junction are defined with supposedly different mechanical resistance to expansion $(22,112)$. Apart from the annulus, which was revealed as the less deformable structure in the root, in this study we observed an increase in longitudinal and circumferential stress and deformation of the PA root using a considerable load. This indicates the stress-shielding characteristic of the PA root, which allows for a uniform distribution of forces to be imparted within the walls and could guarantee relatively long durability. Although the study had insufficient power to draw definitive conclusions about the relative effects of the two types of stresses on the pulmonary conduit, we can speculate that the duration of stress application and the rates of dilation might be associated with the length of the conduit implanted. In our experimental setting, we found no significant changes for PA longer than $3.5 \mathrm{~cm}$, but in the actual surgical practice the correct height of the PA to be implanted is difficult to be determined in children, and the distal anastomosis is normally performed beyond the level of the neo-sinotubular junction in consideration of the somatic growth. For these reasons, a miniroot technique with a reinforcement represents the most appropriate option for this age range, and the use of reinforcing materials that do not impair the compliance of the native PA is important at this stage $(104,105)$. In the young adult ( $>16$ years), when the somatic growth phase is completed, large series demonstrated the importance of reinforcing the PA showing a 6-fold increase in the reoperation rate in subjects who did not receive PA reinforcement $(11,113)$ and linearized occurrence rate (LOR) of reoperation for aortic valve dysfunction of more than $1.8 \%$ /patient-year in case of root replacement technique without reinforcement. In parallel, the use of reinforcement in the miniroot approach could reduce the incidence of aortic regurgitation with LOR $0.32 \% /$ patientyear (6). Other reports, while stressing the significance of measures to stabilize the annulus, demonstrated the superiority of the subcoronary technique in the adult population in terms of autograft durability with freedom from autograft reintervention of $97 \%$ at 10 years and $91 \%$ at 12 years (71). We experimentally found a higher degree of resistance to deformation of the annulus and the valve leaflet of the PA and reports of valve-sparing redo operation for PA failure support this observation. This should theoretically encourage the implant of PA in the subcoronary position and reinforce the concept that pulmonary leaflets do not deteriorate when overpressurized, although the exact time-to-failure cannot be established with certainty $(2-4,22)$. However, besides the progressive clinical abandon of this technique, our results also reveal its biomechanical limitations as the absence of the entire root determines a non-homogeneous distribution of forces concentrating on few points on the leaflets and resulting in cusp degeneration. This idea is confirmed by the report on the long-term outcomes of the GermanDutch Ross Registry which showed that the leading cause of autograft valve failure with the need for reoperation in the subcoronary group was structural valve deterioration ( $80 \%$ of all reoperations), due to cusp prolapse ( $69 \%$ of all structural valve deteriorations) $(6,8,12,113)$.

Conversely, we can strongly support the advantage of the miniroot technique that preserves geometry and function of the pulmonary valve because imparts homogenous distribution of circumferential and longitudinal forces within the entire system of root, annulus, and valve (2$4,22,112)$.

Thirdly, the biomechanical behavior of the PA elucidated in this study confirms the need to support the conduit with reinforcements that could prevent overstressing and dilation, but also comply with the somatic growth process of the patient. These findings inspired the design of semiresorbable reinforcement to be applied during Ross operation $(105,106,110)$.

Recently biomechanical studies advanced our understanding of the relative benefits of PA for the management of severe aortic valve disease. However, it launches a warning about the importance of the choice of the length of the conduits as mechanical deformation, and therefore potential failure increases with the length of the segment subjected to stress. Strengthening of the distal pulmonary root anastomosis using external reinforcement, modifying the ascending phase of the circumferential stress curve, might be advisable as previously described $(105,106,110)$. PA is an ideal substitute for aortic valve replacement not only in Mr. Ross's dreams but also from the biomechanical point of view $(10,95,110,114)$.

\section{Conclusions}

The ideal substitute for treating aortic valve disease in children and young-aged adults remains elusive. The use 
of PA represents the optimal solution as a substitute for the diseased aortic valve that confers efficacy and safety with long-term viability to the aortic root. However, the concern is related to very few randomized studies comparing the use of PA to other valve substitutes for aortic valve replacement (AVR). In fact, the literature reports to date only one randomized controlled study comparing Ross procedure with aortic homograft replacement (13). It is important to note that no randomized study was performed in patients who received the Ross procedure compared to those who were managed with the use of conventional mechanical or stented/non stented prosthesis for AVR. It is clear that the new challenge is to conduct a randomized controlled trial comparing the Ross procedure with conventional AVR. This systematic review confirms that the Ross procedure is the only aortic valve replacement operation that can confer a high potential to achieve not only long-term survival but corresponding to that of people of the same age and sex in the general population. Here we noticed that the appropriate selection patients for whom there is an indication to use the PA is decisive because it allows to perform the Ross procedure safely and reproducibly. Indeed, the evidence has demonstrated excellent long-term freedom from death and valve-related complications-where the procedure is performed in centers of excellence that report high volumes of aortic root surgery. In conclusion the Ross procedure revealed safety and efficacy in both children and young adults due to its adequate biological solution related to the peculiarity of being a living tissue.

\section{Acknowledgments}

Funding: None.

\section{Footnote}

Reporting Checklist: The authors have completed the PRISMA reporting checklist. Available at https:// tp.amegroups.com/article/view/10.21037/tp-21-351/rc

Conflicts of Interest: All authors have completed the ICMJE uniform disclosure form (available at https://tp.amegroups. com/article/view/10.21037/tp-21-351/coif). FN serves as an unpaid editorial board member of Translational Pediatrics from March 2021 to February 2023. The other authors have no conflicts of interest to declare.

Ethical Statement: The authors are accountable for all aspects of the work in ensuring that questions related to the accuracy or integrity of any part of the work are appropriately investigated and resolved.

Open Access Statement: This is an Open Access article distributed in accordance with the Creative Commons Attribution-NonCommercial-NoDerivs 4.0 International License (CC BY-NC-ND 4.0), which permits the noncommercial replication and distribution of the article with the strict proviso that no changes or edits are made and the original work is properly cited (including links to both the formal publication through the relevant DOI and the license). See: https://creativecommons.org/licenses/by-nc-nd/4.0/.

\section{References}

1. Kouchoukos NT, Dávila-Román VG, Spray TL, et al. Replacement of the aortic root with a pulmonary autograft in children and young adults with aortic-valve disease. $\mathrm{N}$ Engl J Med 1994;330:1-6.

2. Nappi F, Spadaccio C, Acar C, et al. Lights and Shadows on the Ross Procedure: Biological Solutions for Biological Problems. Semin Thorac Cardiovasc Surg 2020;32:815-22.

3. Nappi F. Biomechanics of Ross Operation: Still So Much to Learn. Semin Thorac Cardiovasc Surg 2020;32:827-8.

4. Nappi F, Avtaar Singh SS, Spadaccio C, et al. Ross operation 23 years after surgery: It should not be a "forgotten" option. J Card Surg 2020;35:952-6.

5. Takkenberg JJ, Klieverik LM, Schoof PH, et al. The Ross procedure: a systematic review and meta-analysis. Circulation 2009;119:222-8.

6. Mokhles MM, Rizopoulos D, Andrinopoulou ER, et al. Autograft and pulmonary allograft performance in the second post-operative decade after the Ross procedure: insights from the Rotterdam Prospective Cohort Study. Eur Heart J 2012;33:2213-24.

7. Stulak JM, Burkhart HM, Sundt TM 3rd, et al. Spectrum and outcome of reoperations after the Ross procedure. Circulation 2010;122:1153-8.

8. Charitos EI, Takkenberg JJ, Hanke T, et al. Reoperations on the pulmonary autograft and pulmonary homograft after the Ross procedure: An update on the German Dutch Ross Registry. J Thorac Cardiovasc Surg 2012;144:813-21; discussion 821-3.

9. Mazine A, El-Hamamsy I, Verma S, et al. Ross Procedure in Adults for Cardiologists and Cardiac Surgeons: JACC State-of-the-Art Review. J Am Coll Cardiol 2018;72:2761-77. 
10. Nappi F, Nenna A, Spadaccio C, et al. Pulmonary autograft in aortic position: is everything known? Transl Pediatr 2017;6:11-7.

11. Elkins RC, Thompson DM, Lane MM, et al. Ross operation: 16-year experience. J Thorac Cardiovasc Surg 2008;136:623-30, 630.e1-5.

12. Sievers HH, Stierle U, Charitos EI, et al. Major adverse cardiac and cerebrovascular events after the Ross procedure: a report from the German-Dutch Ross Registry. Circulation 2010;122:S216-23.

13. El-Hamamsy I, Eryigit Z, Stevens LM, et al. Longterm outcomes after autograft versus homograft aortic root replacement in adults with aortic valve disease: a randomised controlled trial. Lancet 2010;376:524-31.

14. David TE, David C, Woo A, et al. The Ross procedure: outcomes at 20 years. J Thorac Cardiovasc Surg 2014;147:85-93.

15. Sievers HH, Stierle U, Charitos EI, et al. A multicentre evaluation of the autograft procedure for young patients undergoing aortic valve replacement: update on the German Ross Registry†. Eur J Cardiothorac Surg 2016;49:212-8.

16. Stroup DF, Berlin JA, Morton SC, et al. Meta-analysis of observational studies in epidemiology: a proposal for reporting. Meta-analysis Of Observational Studies in Epidemiology (MOOSE) group. JAMA 2000;283:2008-12.

17. Lauer MS, Blackstone EH, Young JB, et al. Cause of death in clinical research: time for a reassessment? J Am Coll Cardiol 1999;34:618-20.

18. Zanolla L, Zardini P. Selection of endpoints for heart failure clinical trials. Eur J Heart Fail 2003;5:717-23.

19. Sterne JAC, Savović J, Page MJ, et al. RoB 2: a revised tool for assessing risk of bias in randomised trials. BMJ 2019;366:14898.

20. Otto CM, Nishimura RA, Bonow RO, et al. 2020 ACC/ AHA Guideline for the Management of Patients With Valvular Heart Disease: Executive Summary: A Report of the American College of Cardiology/American Heart Association Joint Committee on Clinical Practice Guidelines. Circulation 2021;143:e35-71.

21. Aboud A, Charitos EI, Fujita B, et al. Long-Term Outcomes of Patients Undergoing the Ross Procedure. J Am Coll Cardiol 2021;77:1412-22.

22. Nappi F, Nenna A, Larobina D, et al. Simulating the ideal geometrical and biomechanical parameters of the pulmonary autograft to prevent failure in the Ross operation. Interact Cardiovasc Thorac Surg 2018;27:269-76.

23. Andreas M, Seebacher G, Reida E, et al. A single-center experience with the ross procedure over 20 years. Ann Thorac Surg 2014;97:182-8.

24. da Costa FD, Takkenberg JJ, Fornazari D, et al. Longterm results of the Ross operation: an 18-year single institutional experience. Eur J Cardiothorac Surg 2014;46:415-22; discussion 422.

25. Ruzmetov M, Geiss DM, Shah JJ, et al. Autograft or allograft aortic root replacement in children and young adults with aortic valve disease: a single-center comparison. Ann Thorac Surg 2012;94:1604-11.

26. Luciani GB, Lucchese G, De Rita F, et al. Reparative surgery of the pulmonary autograft: experience with Ross reoperations. Eur J Cardiothorac Surg 2012;41:1309-14; discussion 1314-5.

27. Böhm JO, Hemmer W, Rein JG, et al. A single-institution experience with the Ross operation over 11 years. Ann Thorac Surg 2009;87:514-20.

28. Klieverik LM, Bekkers JA, Roos JW, et al. Autograft or allograft aortic valve replacement in young adult patients with congenital aortic valve disease. Eur Heart J 2008;29:1446-53.

29. Klieverik LM, Takkenberg JJ, Bekkers JA, et al. The Ross operation: a Trojan horse? Eur Heart J 2007;28:1993-2000.

30. Chiappini B, Absil B, Rubay J, et al. The Ross procedure: clinical and echocardiographic follow-up in 219 consecutive patients. Ann Thorac Surg 2007;83:1285-9.

31. Pasquali SK, Shera D, Wernovsky G, et al. Midterm outcomes and predictors of reintervention after the Ross procedure in infants, children, and young adults. J Thorac Cardiovasc Surg 2007;133:893-9.

32. Brown JW, Ruzmetov M, Rodefeld MD, et al. Incidence of and risk factors for pulmonary autograft dilation after Ross aortic valve replacement. Ann Thorac Surg 2007;83:17817; discussion 1787-9.

33. Kumar AS, Talwar S, Mohapatra R, et al. Aortic valve replacement with the pulmonary autograft: mid-term results. Ann Thorac Surg 2005;80:488-94.

34. Sampath Kumar A, Talwar S, Saxena A, et al. Ross procedure in rheumatic aortic valve disease. Eur J Cardiothorac Surg 2006;29:156-61.

35. Kouchoukos NT, Masetti P, Nickerson NJ, et al. The Ross procedure: long-term clinical and echocardiographic follow-up. Ann Thorac Surg 2004;78:773-81; discussion 773-81.

36. Raja SG, Pozzi M. Ross operation in children and young adults: the Alder Hey case series. BMC Cardiovasc Disord 2004:4:3.

37. Alphonso N, Baghai M, Dhital K, et al. Midterm 
results of the Ross procedure. Eur J Cardiothorac Surg 2004;25:925-30.

38. Sakaguchi H, Elkins RC, Lane MM, et al. Effect of prior aortic valve intervention on results of the Ross operation. J Heart Valve Dis 2003;12:423-9.

39. Concha M, Pradas G, Juffé A, et al. Comprehensive experience with the Ross operation in Spain. Eur J Cardiothorac Surg 2003;24:521-6.

40. Takkenberg JJ, Dossche KM, Hazekamp MG, et al. Report of the Dutch experience with the Ross procedure in 343 patients. Eur J Cardiothorac Surg 2002;22:70-7.

41. Pessotto R, Wells WJ, Baker CJ, et al. Midterm results of the Ross procedure. Ann Thorac Surg 2001;71:S336-9.

42. Laudito A, Brook MM, Suleman S, et al. The Ross procedure in children and young adults: a word of caution. J Thorac Cardiovasc Surg 2001;122:147-53.

43. Sharoni E, Katz J, Dagan O, et al. The Ross operation: initial Israeli experience. Isr Med Assoc J 2000;2:115-7.

44. Moidl R, Simon P, Aschauer C, et al. Does the Ross operation fulfil the objective performance criteria established for new prosthetic heart valves? J Heart Valve Dis 2000;9:190-4.

45. Chambers JC, Somerville J, Stone S, et al. Pulmonary autograft procedure for aortic valve disease: long-term results of the pioneer series. Circulation 1997;96:2206-14.

46. Matsuki O, Okita Y, Almeida RS, et al. Two decades' experience with aortic valve replacement with pulmonary autograft. J Thorac Cardiovasc Surg 1988;95:705-11.

47. Gula G, Wain WH, Ross DN. Ten years' experience with pulmonary autograft replacements for aortic valve disease. Ann Thorac Surg 1979;28:392-6.

48. Somerville J, Saravalli O, Ross D, et al. Long-term results of pulmonary autograft for aortic valve replacement. $\mathrm{Br}$ Heart J 1979;42:533-40.

49. Stewart RD, Backer CL, Hillman ND, et al. The Ross operation in children: effects of aortic annuloplasty. Ann Thorac Surg 2007;84:1326-30.

50. Ruzmetov M, Vijay P, Rodefeld MD, et al. Evolution of aortic valve replacement in children: a single center experience. Int J Cardiol 2006;113:194-200.

51. Kalavrouziotis G, Raja S, Ciotti G, et al. Mediumterm results from pulmonary autografts after the Ross procedure in children and adolescents. Hellenic J Cardiol 2006;47:337-43.

52. Böhm JO, Botha CA, Horke A, et al. Is the Ross operation still an acceptable option in children and adolescents? Ann Thorac Surg 2006;82:940-7.

53. Takkenberg JJ, Kappetein AP, van Herwerden LA, et al.
Pediatric autograft aortic root replacement: a prospective follow-up study. Ann Thorac Surg 2005;80:1628-33.

54. Khwaja S, Nigro JJ, Starnes VA. The Ross procedure is an ideal aortic valve replacement operation for the teen patient. Semin Thorac Cardiovasc Surg Pediatr Card Surg Annu 2005;173-5.

55. Hazekamp MG, Grotenhuis HB, Schoof PH, et al. Results of the Ross operation in a pediatric population. Eur J Cardiothorac Surg 2005;27:975-9.

56. Hraska V, Krajci M, Haun Ch, et al. Ross and Ross-Konno procedure in children and adolescents: mid-term results. Eur J Cardiothorac Surg 2004;25:742-7.

57. Al-Halees Z, Pieters F, Qadoura F, et al. The Ross procedure is the procedure of choice for congenital aortic valve disease. J Thorac Cardiovasc Surg 2002;123:437-41; discussion 441-2.

58. Elkins RC, Lane MM, McCue C. Ross operation in children: late results. J Heart Valve Dis 2001;10:736-41.

59. Baumgartner H, Falk V, Bax JJ, et al. 2017 ESC/EACTS Guidelines for the management of valvular heart disease. Eur Heart J 2017;38:2739-91.

60. Mastrobuoni S, de Kerchove L, Solari S, et al. The Ross procedure in young adults: over 20 years of experience in our Institution. Eur J Cardiothorac Surg 2016;49:507-12; discussion 512-3.

61. Buratto E, Shi WY, Wynne R, et al. Improved Survival After the Ross Procedure Compared With Mechanical Aortic Valve Replacement. J Am Coll Cardiol 2018;71:1337-44.

62. Sharabiani MT, Dorobantu DM, Mahani AS, et al. Aortic Valve Replacement and the Ross Operation in Children and Young Adults. J Am Coll Cardiol 2016;67:2858-70.

63. Bouhout I, Poirier N, Mazine A, et al. Cardiac, obstetric, and fetal outcomes during pregnancy after biological or mechanical aortic valve replacement. Can J Cardiol 2014;30:801-7.

64. Mazine A, David TE, Rao V, et al. Long-Term Outcomes of the Ross Procedure Versus Mechanical Aortic Valve Replacement: Propensity-Matched Cohort Study. Circulation 2016;134:576-85.

65. Grunkemeier GL, Li HH, Naftel DC, et al. Long-term performance of heart valve prostheses. Curr Probl Cardiol 2000;25:73-154.

66. Bando K, Danielson GK, Schaff HV, et al. Outcome of pulmonary and aortic homografts for right ventricular outflow tract reconstruction. J Thorac Cardiovasc Surg 1995;109:509-17; discussion 517-8.

67. Skillington PD, Mokhles MM, Takkenberg JJ, et al. The 
Ross procedure using autologous support of the pulmonary autograft: techniques and late results. J Thorac Cardiovasc Surg 2015;149:S46-52.

68. Kalfa D, Feier H, Loundou A, et al. Cryopreserved homograft in the Ross procedure: outcomes and prognostic factors. J Heart Valve Dis 2011;20:571-81.

69. Brown JW, Ruzmetov M, Eltayeb O, et al. Performance of SynerGraft decellularized pulmonary homograft in patients undergoing a Ross procedure. Ann Thorac Surg 2011;91:416-22; discussion 422-3.

70. Hörer J, Hanke T, Stierle U, et al. Neoaortic root diameters and aortic regurgitation in children after the Ross operation. Ann Thorac Surg 2009;88:594-600; discussion 600.

71. Sievers HH, Stierle U, Petersen M, et al. Valve performance classification in 630 subcoronary Ross patients over 22 years. J Thorac Cardiovasc Surg 2018;156:79-86.e2.

72. David TE. Aortic Valve Replacement with Pulmonary Autograft: Subcoronary and Aortic Root Inclusion Techniques. Operative Techniques in Thoracic and Cardiovascular Surgery 2012;17:27-40.

73. Settepani F, Kaya A, Morshuis WJ, et al. The Ross operation: an evaluation of a single institution's experience. Ann Thorac Surg 2005;79:499-504.

74. Takkenberg JJ, van Herwerden LA, Galema TW, et al. Serial echocardiographic assessment of neo-aortic regurgitation and root dimensions after the modified Ross procedure. J Heart Valve Dis 2006;15:100-6; discussion 106-7.

75. Gerestein CG, Takkenberg JJ, Oei FB, et al. Right ventricular outflow tract reconstruction with an allograft conduit. Ann Thorac Surg 2001;71:911-7; discussion 917-8.

76. da Costa FD, Costa AC, Prestes R, et al. The early and midterm function of decellularized aortic valve allografts. Ann Thorac Surg 2010;90:1854-60.

77. Helder MR, Kouchoukos NT, Zehr K, et al. Late durability of decellularized allografts for aortic valve replacement: A word of caution. J Thorac Cardiovasc Surg 2016;152:1197-9.

78. Hogan PG, O'Brien MF. Improving the allograft valve: does the immune response matter? J Thorac Cardiovasc Surg 2003;126:1251-3.

79. Cebotari S, Tudorache I, Ciubotaru A, et al. Use of fresh decellularized allografts for pulmonary valve replacement may reduce the reoperation rate in children and young adults: early report. Circulation 2011;124:S115-23.

80. Berdajs DA, Muradbegovic M, Haselbach D, et al. Ross procedure: is the root replacement technique superior to the sub-coronary implantation technique? Long-term results. Eur J Cardiothorac Surg 2014;46:944-51.

81. Sievers HH, Hanke T, Stierle U, et al. A critical reappraisal of the Ross operation: renaissance of the subcoronary implantation technique? Circulation 2006;114:I504-11.

82. David TE, Woo A, Armstrong S, et al. When is the Ross operation a good option to treat aortic valve disease? J Thorac Cardiovasc Surg 2010;139:68-73; discussion 73-5.

83. Nappi F, Singh SSA, Bellomo F, et al. The Choice of Pulmonary Autograft in Aortic Valve Surgery: A State-ofthe-Art Primer. Biomed Res Int 2021;2021:5547342.

84. David TE, Omran A, Ivanov J, et al. Dilation of the pulmonary autograft after the Ross procedure. J Thorac Cardiovasc Surg 2000;119:210-20.

85. Nappi F, Spadaccio C, Fouret P, et al. An experimental model of the Ross operation: Development of resorbable reinforcements for pulmonary autografts. J Thorac Cardiovasc Surg 2015;149:1134-42.

86. Nappi F, Spadaccio C, Fraldi M, et al. A composite semiresorbable armoured scaffold stabilizes pulmonary autograft after the Ross operation: Mr Ross's dream fulfilled. J Thorac Cardiovasc Surg 2016;151:155-64.e1.

87. David TE, Omran A, Webb G, et al. Geometric mismatch of the aortic and pulmonary roots causes aortic insufficiency after the Ross procedure. J Thorac Cardiovasc Surg 1996;112:1231-7; discussion 1237-9.

88. Nappi F, Spadaccio C, Castaldo C, et al. Reinforcement of the pulmonary artery autograft with a polyglactin and polydioxanone mesh in the Ross operation: experimental study in growing lamb. J Heart Valve Dis 2014;23:145-8.

89. Basmadjian L, Basmadjian AJ, Stevens LM, et al. Early results of extra-aortic annuloplasty ring implantation on aortic annular dimensions. J Thorac Cardiovasc Surg 2016;151:1280-5.e1.

90. Mazine A, Ghoneim A, El-Hamamsy I. The Ross Procedure: How I Teach It. Ann Thorac Surg 2018;105:1294-8.

91. Brown JW, Ruzmetov M, Shahriari AP, et al. Modification of the Ross aortic valve replacement to prevent late autograft dilatation. Eur J Cardiothorac Surg 2010;37:1002-7.

92. Carrel T, Kadner A. Long-Term Clinical and Imaging Follow-Up After Reinforced Pulmonary Autograft Ross Procedure. Semin Thorac Cardiovasc Surg Pediatr Card Surg Annu 2016;19:59-62.

93. Forcillo J, Cikirikcioglu M, Poirier N, et al. The Ross procedure: total root technique. Multimed Man 
Cardiothorac Surg 2014;2014:mmu018.

94. Spadaccio C, Montagnani S, Acar C, et al. Introducing bioresorbable scaffolds into the show. A potential adjunct to resuscitate Ross procedure. Int J Cardiol 2015;190:50-2.

95. Nappi F, Spadaccio C, Al-Attar N, et al. The Ross procedure at the crossroads: lessons from biology: is Dr Ross's dream concluded? Int J Cardiol 2015;178:37-9.

96. Nataf P, Guettier C, Bourbon A, et al. Influence of arterial allograft preparation techniques on chronic vascular rejection: a histological study. Transplant Proc 1996;28:2890-2.

97. Spadaccio C, Rainer A, Mozetic P, et al. The role of extracellular matrix in age-related conduction disorders: a forgotten player? J Geriatr Cardiol 2015;12:76-82.

98. Spadaccio C, Mozetic P, Nappi F, et al. Cells and extracellular matrix interplay in cardiac valve disease: because age matters. Basic Res Cardiol 2016;111:16.

99. Carr-White GS, Afoke A, Birks EJ, et al. Aortic root characteristics of human pulmonary autografts. Circulation 2000;102:III15-21.

100. Rabkin-Aikawa E, Aikawa M, Farber M, et al. Clinical pulmonary autograft valves: pathologic evidence of adaptive remodeling in the aortic site. J Thorac Cardiovasc Surg 2004;128:552-61.

101. Schoof PH, Takkenberg JJ, van Suylen RJ, et al. Degeneration of the pulmonary autograft: an explant study. J Thorac Cardiovasc Surg 2006;132:1426-32.

102. Gorczynski A, Trenkner M, Anisimowicz L, et al. Biomechanics of the pulmonary autograft valve in the aortic position. Thorax 1982;37:535-9.

103. Chiarini A, Dal Prà I, Faggian G, et al. Maladaptive remodeling of pulmonary artery root autografts after Ross procedure: A proteomic study. J Thorac Cardiovasc Surg 2020;159:621-632.e3.

104. Nappi F, Carotenuto AR, Cutolo A, et al. Compliance mismatch and compressive wall stresses drive anomalous remodelling of pulmonary trunks reinforced with Dacron grafts. J Mech Behav Biomed Mater 2016;63:287-302.

Cite this article as: Nappi F, Iervolino A, Avtaar Singh SS. The effectiveness and safety of pulmonary autograft as living tissue in Ross procedure: a systematic review. Transl Pediatr 2022;11(2):280-297. doi: 10.21037/tp-21-351
105.Nappi F, Carotenuto AR, Di Vito D, et al. Stress-shielding, growth and remodeling of pulmonary artery reinforced with copolymer scaffold and transposed into aortic position. Biomech Model Mechanobiol 2016;15:1141-57.

106. Nappi F, Fraldi M, Spadaccio C, et al. Biomechanics drive histological wall remodeling of neoaortic root: A mathematical model to study the expression levels of ki 67 , metalloprotease, and apoptosis transition. J Biomed Mater Res A 2016;104:2785-93.

107. Spadaccio C, Nappi F, Al-Attar N, et al. Old Myths, New Concerns: the Long-Term Effects of Ascending Aorta Replacement with Dacron Grafts. Not All That Glitters Is Gold. J Cardiovasc Transl Res 2016;9:334-42.

108. Mookhoek A, Krishnan K, Chitsaz S, et al. Biomechanics of Failed Pulmonary Autografts Compared With Normal Pulmonary Roots. Ann Thorac Surg 2016;102:1996-2002.

109. Mookhoek A, Krishnan K, Chitsaz S, et al. Biomechanics of Failed Pulmonary Autografts Compared to Native Aortic Roots. Ann Thorac Surg 2017;103:1482-8.

110. Nappi F, Nenna A, Lemmo F, et al. Finite Element Analysis Investigate Pulmonary Autograft Root and Leaflet Stresses to Understand Late Durability of Ross Operation. Biomimetics (Basel) 2020;5:37.

111. Vesely I, Casarotto DC, Gerosa G. Mechanics of cryopreserved aortic and pulmonary homografts. J Heart Valve Dis 2000;9:27-37.

112. Acar C, Varnous S. In response to Kazui T, Izumoto H, Yoshioka K, Kawazoe K. Dynamic morphologic changes in the normal aortic annulus during systole and diastole. J Heart Valve Dis 2006;15:617-21. J Heart Valve Dis 2006; 15:843.

113. Charitos EI, Hanke T, Stierle U, et al. Autograft reinforcement to preserve autograft function after the ross procedure: a report from the german-dutch ross registry. Circulation 2009;120:S146-54.

114. Yacoub MH, El-Hamamsy I, Sievers HH, et al. Underuse of the Ross operation--a lost opportunity. Lancet 2014;384:559-60. 